\title{
(DES)CONFORMIDADE DO PROCESSO DE TRABALHO NO CENTRO DE MATERIAL E ESTERILIZAÇÃO
}

\author{
(Dis)conformity of the working process in the material and sterilization center
}

\author{
(Des)conformidad del proceso de trabajo en el centro de material y esterilización
}
Luciana Santana Lobo Silva ${ }^{*}$ (D), Maria Pontes de Aguiar Campos $^{2}$ (D), Flávia Janólio Costacurta Pinto da Silva ${ }^{3}$ (D)

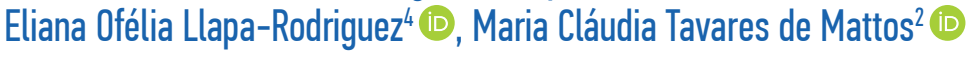

RESUMO: Objetivo: Avaliar o processo de trabalho de enfermagem em um Centro de Material e Esterilização (CME) de um hospital de ensino no Nordeste brasileiro e calcular os índices de conformidades dos processos de trabalho dos produtos para saúde (PPS) hospitalares no CME. Método: Estudo observacional, com análises quantitativas. A população-alvo constituiu-se de técnicos e auxiliares de enfermagem, por meio de observação sistemática no desenvolvimento dos processos de trabalho. A amostra resultou em 24 profissionais, correspondendo a $80 \%$ da população. Resultados: Dos processos observados, o índice de conformidade foi menor (29,17\%) na esterilização e maior (56,94\%) na guarda/ distribuição dos produtos. Quanto aos subprocessos, foi maior $(90,28 \%)$ na selagem e menor $(8,33 \%)$ no enxágue dos PPS. Conclusão: A média de conformidade dos processos apresentou índice abaixo do limite de $70 \%$, comprometendo a maioria do processo de trabalho da equipe de enfermagem.

Palavras-chave: Indicadores de qualidade em assistência à saúde. Esterilização. Avaliação de desempenho profissional.

ABSTRACT: Objectives: To evaluate the nursing work process in a Material and Sterilization Center (MSC) of a teaching hospital in Northeastern Brazil and to calculate the compliance rates of the work processes of hospital health products (HP) in the CME. Method: Observational study, with quantitative analyses. The target population consisted of nursing technicians and assistants, through systematic observation in the development of work processes. The sample resulted in 24 professionals, corresponding to $80 \%$ of the population. Results: Of the observed processes, the compliance rate was lower $(29.17 \%)$ in sterilization and higher (56.94\%) in the storage/distribution of the products. As for subprocesses, it was higher (90.28\%) in sealing and lower $(8.33 \%)$ in rinsing the HP. Conclusion: The average process compliance showed an index below the limit of $70 \%$, compromising most of the nursing team's work process.

Keywords: Quality indicators, health care. Sterilization. Employee performance appraisal.

RESUMEN: Objetivos: Evaluar el proceso de trabajo de enfermería en un Centro de Material y Esterilización (CME) de un hospital docente en el noreste de Brasil y calcular las tasas de cumplimiento de los procesos de trabajo de productos de salud (PS) en hospitales en CME. Método: Estudio observacional, con análisis cuantitativos. La población objetivo consistió en técnicos de enfermería y asistentes, a través de la observación sistemática en el desarrollo de procesos de trabajo. La muestra resultó en 24 profesionales, que corresponden al 80\% de la población. Resultados: De los procesos observados, la tasa de cumplimiento fue menor (29.17\%) en esterilización y mayor (56.94\%) en el almacenamiento / distribución de productos. En cuanto a los subprocesos, fue mayor (90.28\%) en sellado y menor (8.33\%) en enjuague del PS. Conclusión: El cumplimiento promedio del proceso mostró un índice por debajo del límite del 70\%, comprometiendo la mayor parte del proceso de trabajo del equipo de enfermería. Palablas clave: Indicadores de calidad de la atención de salud. Esterilización. Evaluación del rendimiento de empleados.

'Graduada em Enfermagem (Bacharelado) pela Universidade Tiradentes (Unit). Mestre pelo Programa de Pós-graduação em Enfermagem da Universidade Federal de Sergipe (UFS). Especialista em Enfermagem em Urgência e Emergência Pré-Hospitalar e Enfermagem Ginecológica e Obstétrica pela Unit. Enfermeira assistencial na Maternidade Nossa Senhora de Lourdes - Aracaju (SE), Brasil.

2Professora doutora do Departamento de Enfermagem e do Programa de Pós-graduação em Enfermagem da UFS - Aracaju (SE), Brasil.

${ }^{3}$ Professora doutora do Departamento de Enfermagem da UFS. Chefe da Divisão de Enfermagem do Hospital Universitário de Sergipe - Aracaju (SE), Brasil.

"Professora pós-doutora do Departamento de Enfermagem e do Programa de Pós-graduação em Enfermagem da UFS - Aracaju (SE), Brasil.

*Autora correspondente: lucys lobo@yahoo.com.br

Recebido: 15/07/2019 - Aprovado: 20/01/2020

DOI: 10.5327/Z1414-4425202000010002 


\section{INTRODUÇÃ̃O}

Historicamente, o Centro de Material e Esterilização (CME) era responsável apenas pela etapa de esterilização. A partir de 1970, o espectro de atuação do CME foi ampliando-se e, no final do século XX, passou a executar todos os processos devido à exigência de estrutura física única e apropriada, recursos humanos qualificados e complexidade dos produtos ${ }^{1,2}$.

Assim, o funcionamento do CME passou ser centralizado, atendendo aos serviços que necessitam processar os produtos para saúde (PPS) ${ }^{3}$, por meio de boas práticas, prevenindo as infecções relacionadas à assistência à saúde (IRAS), principalmente às falhas em quaisquer das etapas ${ }^{2}$.

Logo, para avaliar a qualidade da assistência realizada no CME, existem indicadores de estrutura; recursos materiais e humanos; política organizacional; processos-atividades que, ao serem executados, transformam insumos em resultados; e esses resultados indicam um produto seguro e satisfatório ${ }^{4}$.

Esta pesquisa justifica-se devido à constatação empírica de inconformidades nos processamentos dos produtos ${ }^{3}$. Assim, pretende-se contribuir com um diagnóstico situacional que possibilitará investimentos para assegurar uma assistência mais adequada e mais padronizada, visando a excelência assistencial.

Portanto, pretendeu-se responder ao questionamento: quais processos de trabalho, executados pelos profissionais de enfermagem no CME de um hospital de ensino, apresentam índices de conformidades?

\section{OBJETIVOS}

- Analisar o processo de trabalho da equipe de enfermagem no CME de um hospital de ensino no Nordeste brasileiro.

- Calcular os índices de conformidades dos processos de trabalho dos PPS hospitalares no CME.

\section{MÉTODO}

Trata-se de um estudo observacional, cujos dados foram tratados por métodos quantitativos. O universo foi um hospital de ensino, localizado no Nordeste Brasileiro, que presta assistência hospitalar de média e alta complexidade aos usuários do Sistema Único de Saúde (SUS), sendo campo para pesquisa e extensão. A unidade de observação foi o CME, classificado como tipo $\mathrm{II}^{3}$.

A população-alvo foi constituída de 30 técnicos e auxiliares de enfermagem, dos três turnos de trabalho, por meio de observação sistemática no desenvolvimento dos processos de trabalho. A amostra, por conveniência, foi composta de $80 \%$ dos profissionais de enfermagem (24), garantindo a homogeneidade dos fatos.

Os critérios de inclusão foram: estar lotado e presente no CME nos dias de coleta de dados. O critério de exclusão foi: ausência devido a férias, licença, folgas e faltas.

$O$ instrumento de coleta de dados foi uma checklist adaptada de Graziano e colaboradores ${ }^{5}$, após ser autorizada por esses autores e fundamentada nas normas vigentes nacionais ${ }^{3}$ e internacionais ${ }^{6-8}$. Realizou-se teste piloto que, após adequações, ficou composto de 102 itens correspondentes aos processos de limpeza, desinfecção química, preparo, esterilização, guarda/ acondicionamento e distribuição.

Cada profissional foi observado apenas uma vez na realização completa de cada processo.

Foram considerados conformes os processos presentes e conformes (PC) e desconformes os processos presentes não conformes (PNC) e os processos ausentes (AS). Os dados foram analisados pelo Statistical Package for the Social Science (SPSS) ${ }^{\circledR} 21.0$.

Para as variáveis qualitativas, em relação à caracterização da amostra, realizou-se análise descritiva, obtenção das frequências e percentuais. Para as variáveis quantitativas, utilizou-se estatística descritiva, pelo cálculo das medidas de tendência central (média) e variabilidade (desvio padrão).

Utilizou-se nível de significância de $5 \%(\mathrm{p} \leq 0,05)$, teste $t$ de Student, para comparações aos pares com os dados normais, análise de variância ANOVA para dados que seguem a distribuição normal e teste de Tukey para os que não apresentaram normalidade. Mediante o cálculo do índice de positividade de Carter (IPC) ${ }^{9}$, os processos analisados em conformidade foram classificados: IPC de $100 \%$ assistência desejável; 90-99\% — adequada; $80-89 \%$ segura; 70-79\% - limítrofe; e abaixo de 70\% — sofrível. Para este estudo, foram considerados de qualidade os itens que apresentaram IPC igual ou superior a $80 \%$ para segurança dos processos.

O projeto foi analisado e aprovado pelo CEP da Instituição sede da pesquisa (CAAE: 57210916.0.0000.5546) e integra a dissertação de Mestrado em Enfermagem intitulada Avaliação do trabalho da equipe de enfermagem em um Centro de Material e Esterilização. 


\section{RESULTADOS}

Caracterizando a amostra, identificou-se que dos 24 profissionais de enfermagem, $54,17 \%$ (13) eram técnicos de enfermagem, 45,83\% (11) auxiliares, sendo $91,67 \%$ (22) do sexo biológico feminino, $33,33 \%$ (8) trabalhavam no turno matutino, $29,17 \%$ (7) no vespertino e $37,50 \%$ (9) nos plantões noturnos.

A idade variou entre 26 e 54 anos, com média de 37,62 anos. O tempo médio de trabalho foi de aproximadamente três anos no hospital, um ano no setor em estudo, caracterizando profissionais com pouco tempo de atuação. Quanto à qualificação em CME, 54,17\% (13) não a possuía, 45,83\% (11) tinham aprimoramento e participação em educação em serviço.

Em referência à categoria profissional, constatou-se relação estatisticamente significante com o processo de esterilização; no entanto, a qualificação profissional e o índice de conformidade não apresentaram relação estatística significativa. Os auxiliares de enfermagem apresentaram média de conformidade maior que os técnicos.

$\mathrm{O}$ índice de conformidade dos processos observados no CME foi baixo. A menor taxa foi na esterilização e a maior na guarda/distribuição dos produtos (Tabela 1).

Considerou-se vestimenta completa, uso de roupa privativa, gorro, sapato fechado e propé. Analisando essa variável (Tabela 2), a maior média de conformidade foi observada na limpeza $(66,67 \%)$ e a menor no preparo $(46,87 \%)$. Entre os elementos da vestimenta completa, o uso de sapato fechado apresentou menor índice de conformidade, sendo o uso incorreto ou não uso na limpeza igual a 58,33\% (14), desinfecção $70,83 \%$ (17), preparo $87,50 \%$ (21), esterilização e guarda/distribuição $83,33 \%$ (20). A roupa privativa apresentou conformidade em $95,83 \%$ (23) dos casos, considerada adequada. Os demais elementos da vestimenta completa encontravam-se, em sua maioria, PNC ou AS. Constatou-se

Tabela 1. Taxa média de conformidade e IPC dos processos de trabalho no CME.

\begin{tabular}{|l|c|c|c|}
\hline Setores & $\begin{array}{c}\text { Média de } \\
\text { conformidade }\end{array}$ & $\begin{array}{c}\text { Desvio } \\
\text { padrão }\end{array}$ & IPC \\
\hline Limpeza & 41,38 & 05,80 & Sofrível \\
\hline Desinfecção química & 41,22 & 11,91 & Sofrível \\
\hline Preparo & 50,77 & 04,14 & Sofrível \\
\hline Esterilização & 29,17 & 05,84 & Sofrível \\
\hline Guarda/Distribuição & 56,94 & 09,08 & Sofrível \\
\hline
\end{tabular}

IPC: índice de positividade de Carter; CME: Centro de Material e Esterilização. que $62,50 \%$ (15) dos profissionais utilizavam adornos, como brincos longos e correntes.

Quanto ao uso dos equipamentos de proteção individual (EPI), foram observados: luvas (cano longo, procedimento e térmica), óculos de proteção, máscara simples, avental, capa impermeável e protetor auricular. Obteve-se maiores médias de conformidades na guarda / distribuição dos materiais e na desinfecção, com 58,33 e 30,55\% respectivamente, considerados uma assistência sofrível.

Constatou-se que o uso da máscara simples se apresentava em conformidade, embora com menores taxas nos processos de preparo $54,17 \%$ (13). No processo de limpeza, estava AS em 100\% (24) das observações, uso da luva de cano longo, avental, capa impermeável, óculos de proteção em 75 (18) e $79,17 \%$ (19) na desinfecção, todos considerados sofríveis.

No preparo, comprovou-se que $75 \%$ (18) dos colaboradores não utilizavam luva de procedimento ao manusear artigos críticos lavados. Salienta-se que, em 100\% (24) das situações, não houve higienização das mãos antes e depois da execução dos processos, evidenciando assistência sofrível.

A média de conformidade dos processos, denominados neste estudo subprocessos (Tabela 3), que obtiveram maiores conformidades, foram montagem $(81,25 \%)$, selagem $(90,28 \%)$ e separação $(83,33 \%)$; opostamente, o enxágue dos artigos semicríticos apresentou menor conformidade $(8,33 \%)$ na desinfecção.

Na Limpeza, constatou-se que o subprocesso Recepção dos PPS PNC foram: conferência de materiais semicríticos

Tabela 2. Taxa média de conformidade e IPC no uso da vestimenta completa e EPI, segundo os processos de trabalho no CME.

\begin{tabular}{|l|c|c|c|c|}
\hline Conformidade & & Média & $\begin{array}{c}\text { Desvio } \\
\text { padrão }\end{array}$ & IPC \\
\hline Limpeza & Vestimenta & 66,67 & 24,08 & Sofrível \\
\hline Desinfecção & EPI & 29,17 & 13,64 & \\
\hline \multirow{2}{*}{ Preparo } & Vestimenta & 53,12 & 18,52 & Sofrível \\
\hline \multirow{2}{*}{ Esterilização } & EPI & 30,55 & 09,41 & \\
\hline \multirow{2}{*}{ Gestimenta } & 46,87 & 16,99 & Sofrível \\
\hline & EPI & 14,58 & 31,20 & \\
\hline & Vestimenta & 48,96 & 20,16 & Sofrível \\
\hline & EPI & 16,67 & 38,07 & \\
\hline & Vestimenta & 47,92 & 22,01 & Sofrível \\
\hline
\end{tabular}

IPC: índice de positividade de Carter; EPI: equipamento de proteção individual; CME: Centro de Material e Esterilização. 
contaminados $75 \%$ (18), críticos $83,33 \%$ (20) e registro de controle de entrada de materiais $95,83 \%$ (23).

Na Pré-limpeza, estavam PNC 83,33\% (20) em relação à diluição do detergente enzimático; 45,43\% (11) não utilizaram recipientes graduados para diluição; 70,83\% (17) não realizaram a lavagem dos materiais em água corrente; opostamente, 66,67\% (16) desmontaram os artigos antes da submersão no detergente, caracterizando-se assistência sofrível.

Na Lavagem, evidenciou-se PNC, 91,67\% (22) não utilizaram esponja indicada; $45,83 \%$ (11) não enxaguaram peça por peça; $75 \%$ (18) não submergiram completamente os artigos críticos e semicríticos no detergente enzimático; 70,83\% (17) não atendiam o tempo preconizado; $62,50 \%$ (15) não realizaram a fricção no sentido das ranhuras e $100 \%$ (24) dos artigos lavados manualmente não foram escovados submersos na solução enzimática.

Além disso, 79,17\% (19) da lavagem dos artigos críticos foi complementada com limpeza automatizada; $87,50 \%$ (21)

Tabela 3. Taxas médias de conformidade e IPC dos subprocessos realizados no CME.

\begin{tabular}{|c|c|c|c|}
\hline Subprocessos & Média & $\begin{array}{l}\text { Desvio } \\
\text { padrão }\end{array}$ & IPC \\
\hline \multicolumn{4}{|l|}{ Limpeza } \\
\hline Recepção & 15,28 & 29,97 & Sofrível \\
\hline Pré-limpeza & 52,08 & 17,16 & Sofrível \\
\hline Lavagem & 38,89 & 07,74 & Sofrível \\
\hline Secagem & 41,15 & 07,80 & Sofrível \\
\hline \multicolumn{4}{|l|}{ Desinfecção } \\
\hline Validação/Diluição & 61,67 & 16,59 & Sofrível \\
\hline Imersão & 31,25 & 43,77 & Sofrível \\
\hline Enxágue & 08,33 & 19,03 & Sofrível \\
\hline Secagem & 66,67 & 00,00 & Sofrível \\
\hline \multicolumn{4}{|l|}{ Preparo } \\
\hline Inspeção/Funcionalidade & 20,83 & 15,18 & Sofrível \\
\hline Montagem & 81,25 & 13,29 & Segura \\
\hline Monitoramento & 62,50 & 22,12 & Sofrível \\
\hline Selagem & 90,28 & 15,48 & Adequada \\
\hline \multicolumn{4}{|l|}{ Esterilização } \\
\hline Monitorização & 17,71 & 11,61 & Sofrível \\
\hline Disposição na autoclave & 59,72 & 27,76 & Sofrível \\
\hline Inspeção pós-esterilização & 75,00 & 39,01 & Limítrofe \\
\hline \multicolumn{4}{|l|}{ Guarda/ Distribuição } \\
\hline Estocagem & 12,50 & 33,78 & Sofrível \\
\hline Separação & 83,33 & 28,23 & Segura \\
\hline
\end{tabular}

IPC: índice de positividade de Carter; CME: Centro de Material e Esterilização. abriram os instrumentais, alcançando ao mesmo tempo assistência limítrofe e segura, entretanto $54,17 \%$ (13) realizaram o enxágue corretamente. Todos os artigos críticos e semicríticos (100\% / 24) eram secos manualmente, de forma adequada e em índice desejável; entretanto, não eram secos imediatamente após a lavagem.

Os artigos desinfetados foram os semicríticos termossensíveis, sendo verificados índices seguros de conformidade na diluição do desinfetante $83,33 \%$ (20), na identificação do recipiente quanto ao prazo de validade da diluição $87,50 \%$ (21). Os PNC foram $66,67 \%$ (16) a não submersão completa dos materiais e 70,83\% (17) o tempo preconizado de submersão. No subprocesso Enxágue, houve PNC 83,33\% (20) no tempo de duração e PC $100 \%$ (24) dos artigos eram secos adequadamente com fluxo de ar.

No preparo dos artigos para esterilização, notou-se que se encontrava PC 70,83\% (17) observação de rasgos, furos e cerzidos nos tecidos; $100 \%$ (24) colocação de absorvente no fundo do estojo; 79,17\% (19) acondicionamento dos instrumentais cirúrgicos nas caixas obedecendo $80 \%$ da sua capacidade; $83,33 \%$ (20) foram dispostos abertos; 95,83\% (23) dos envelopamentos estavam justos; $100 \%$ (24) utilizaram indicador externo e $75 \%$ (18) interno. PNC, 91,67\% (22) não inspecionavam os instrumentais quanto à funcionalidade $\mathrm{e}$ $100 \%$ (24) não verificavam a limpeza com lente de aumento, devido AS relativos a esta última.

No subprocesso Monitoramento, a identificação dos artigos foi AS em 100\% (24) quanto ao registro do número da carga ou lote que seriam esterilizados. Contudo, estavam PC 95,83\% (23) os registros de identificação das caixas cirúrgicas, $91,67 \%$ (22) quantidade de peças e $100 \%$ (24) a data de esterilização e validade.

Quanto ao subprocesso Selagem, em termosseladora, verificou-se conformidade em $100 \%$ (24) das embalagens tipo grau cirúrgico, em 95,83\% (23) a temperatura atendia às normas e $75 \%$ (18) selaram a embalagem primária e secundária fundamentado no peso e na natureza do material, demonstrando resultados adequados.

No processo de Esterilização, a monitorização apresentou $100 \%$ (24) de conformidade no teste Bowie-Dick e no teste biológico, contudo o segundo é exclusivo do enfermeiro, tanto o preparo, quanto a leitura. Estavam AS 100\% (24) das ações referentes ao registro de controle de entrada de carga por autoclave. Com relação à disposição dos artigos na autoclave, houve conformidade no posicionamento dos pacotes em $62,50 \%$ (15) das ações, 79,17\% (19) obedeceu à folga entre eles e 95,83\% (23) dos artigos côncavo-convexos 
foram dispostos na posição vertical/inclinados, conferindo índices sofríveis, limítrofes e adequados.

Após a esterilização, 75\% (18) dos colaboradores inspecionaram os pacotes para conferir a presença de umidade e o resfriamento. Salienta-se que a higienização da câmera interna da autoclave não era realizada.

No processo de Guarda / Distribuição, a média de desconformidade relacionada ao subprocesso Estocagem apresentou elevado percentual, pois $87,50 \%$ (21) não obedeceu a ordem cronológica de esterilização. Todavia, 95,83\% (23) acondicionaram os artigos críticos e semicríticos em local limpo, seco, separando artigos desinfetados dos esterilizados e protegidos dos raios solares, caracterizando-se ação adequada.

\section{DISCUSSÃO}

Os processos desenvolvidos no CME são complexos, destarte ressalta-se a relevância da sua validação, pois previne a contaminação, controla a qualidade e evita as IRAS. Assim, os profissionais de enfermagem devem adotar as regulamentações nacionais/internacionais e receber capacitações periódicas ${ }^{2}$.

O perfil observado era composto, em sua maioria, de mulheres jovens, com pouco tempo de atuação no CME e sem qualificação profissional específica. Tal resultado aproximou-se ao do perfil do estudo realizado pelo $\mathrm{COFEN}^{10} \mathrm{em}$ um hospital de ensino no estado do Rio de Janeiro ${ }^{11}$. Quanto à idade, esta semelhança pode ter ocorrido pelo fato de a instituição em investigação ter realizado concurso público pouco tempo antes da pesquisa.

A maioria dos processos de trabalho observados apresentaram índices de conformidade abaixo do limítrofe para uma assistência desejável, considerando-se o IPC similar às pesquisas realizadas em São Paulo ${ }^{12}$, Bahia ${ }^{13}$ e Piauí ${ }^{14}$. Esse resultado pode ser reflexo da população ser majoritariamente de recém-admitidos, sem experiência nessa unidade e sem participação em programa de educação continuada. Logo, as práticas de educação permanente superam dificuldades, podem padronizar e reduzir falhas e estimular uma cultura de segurança ${ }^{15}$.

Constatou-se que os auxiliares de enfermagem apresentaram maior taxa de conformidade nos processamentos do que os técnicos de enfermagem. Esse achado pode ser justificado por os auxiliares terem mais tempo de atuação na instituição e serem mais experientes.

Correlacionando a taxa de conformidade dos processos com a qualificação profissional, verificou-se não haver relação estatisticamente positiva. Ter ou não qualificação, nessa amostra, não interferiu nas taxas de conformidades. Contudo, esse achado não diminui a importância atribuída às capacitações, comprovada por estudos científicos que recomendaram aos profissionais do CME capacitações periódicas ${ }^{3}$. Tal resultado pode ser justificado em razão da amostra ser pequena.

A vestimenta completa é indispensável a todos que atuam no CME, para promover segurança ao profissional, a sua família e ao paciente ${ }^{6}$, entretanto foi observado em desconformidade, principalmente pelo uso inadequado do sapato fechado, propés e adornos. Em relação ao uso dos propés, provavelmente por causa da razão de se encontrar na literatura científica específica fortes divergências quanto à sua eficácia, pode-se induzir condutas isoladas de não utilização.

Embora o uso e a disposição dos EPI sejam imprescindíveis para a segurança do profissional ${ }^{16}$, observou-se que se encontravam desconformes, principalmente na limpeza e no preparo, de maneira semelhante ao resultado obtido em pesquisa realizada nos estados da Bahia ${ }^{13}$ e de Minas Gerais ${ }^{17}$, mas diferentemente das observações encontradas no Rio Grande do Sul ${ }^{18}$, onde havia cultura de segurança entre os profissionais. Tal achado divergente talvez se justifique pelo fato de o Rio Grande do Sul investir mais em Programas Permanentes de educação para a saúde e cursos de atualização para seus servidores ${ }^{19}$.

Os setores no CME exigem o uso completo de EPI: luvas impermeáveis ao comprimento do cotovelo, térmicas ${ }^{7}$ e de procedimentos, avental impermeável com mangas longas, máscara facial ou óculos de proteção, protetor auricular e máscaras simples ${ }^{3,15,20}$, principalmente no expurgo ${ }^{6}$, contudo o uso completo apresentou desconformidade proveniente da inexistência de alguns EPI.

$\mathrm{Na}$ área de Preparo, a média de conformidade foi menor no uso da vestimenta completa e no uso de EPI, principalmente de luvas para o preparo das caixas cirúrgicas, que poderá expor os profissionais a doenças ocupacionais. Estudo francês realizado em hospital de ensino sobre uso de luvas, verificou que os profissionais treinados aderiam mais em relação aos não treinados ${ }^{21}$. Esse resultado está de acordo com o encontrado no presente estudo, referente à qualificação profissional que apresentou baixos índices, podendo ter corroborado para o descumprimento no uso dos EPI nesse ambiente.

Outro resultado desfavorável foi a não higienização das mãos pelos profissionais, infringindo o recomendado da indispensabilidade dessa ação, antes de iniciar o trabalho, ao concluí-lo, durante as pausas, depois de remover as luvas e sempre quando as mãos estiverem contaminadas? ${ }^{7}$. 
Os PPS se tornaram cada vez mais complexos, o que exige limpeza automatizada, enxágue abundante e secagem $^{22}$. O processo de limpeza observado, em sua maioria, apresentou desconformidade referente ao uso dos insumos e desempenho, contrariando a normalização ${ }^{3}$ e possibilitando formação de biofilme, que interfere na ação do esterilizante e aumenta os riscos ocupacionais².

Um estudo sobre a contaminação por príons após limpeza e esterilização constatou que a descontaminação ocorreu após o ciclo completo no processamento, isto é, para que alcançasse um resultado seguro, dependeu do processo, insumos, temperatura e tempo na esterilização física e físico-química ${ }^{23}$. Assim, a limpeza automatizada era executada e o manuseio da lavadora obedecia às recomendações, dado antagônico ao encontrado na pesquisa realizada em estabelecimentos de saúde públicos em Santa Catarina ${ }^{24}$.

Em referência ao Enxague dos PPS, este deve ser realizado em água corrente abundante, sem deixar resquício do saneante. Contrariamente à literatura específica ${ }^{2,20}$, observou-se falha nesse processo, tendo como consequência quebra da efetividade que interfere na segurança do produto.

O subprocesso Secagem, relevante para esterilização/desinfecção, previne crescimento bacteriano e evita inatividade dos desinfetantes pela hiperdiluição, devendo secar ao ar quente ou à mão com uma toalha limpa que não solte partículas ${ }^{7}$. Todavia, constatou-se que o material lavado era deixado na bancada para secar ao ar ambiente e colocado para desinfecção antes da secagem, o que poderia provocar perda da eficácia do saneante ${ }^{2}$.

Quanto à inobservância da identificação dos pacotes relacionada ao número da autoclave, lote ou carga e identificação do montador, contraria as normas internacionais ${ }^{6}$, resultando na dificuldade ou na impossibilidade do rastreamento dos artigos ${ }^{3,8}$. Dessa forma, além da indispensabilidade das informações, o registro deve ser legível, com tinta atóxica e que não borre. Entretanto, para os campos de tecido, é permitida a identificação na fita adesiva na inexistência das etiquetas autocolantes ${ }^{6}$, como constatado nesta e em unidades hospitalares do Rio Grande do Sul ${ }^{25}$. Esta rotina difere da pesquisa em hospital de ensino em São Paulo, pois a identificação era feita por etiquetadora de rastreabilidade ${ }^{26}$.

A inspeção dos campos seguiu o preconizado pelas normas $^{3,6}$, contribuindo para a segurança do paciente. Situação oposta foi encontrada em estabelecimentos públicos na cidade de Goiânia, estado de Goiás ${ }^{1}$.

Para garantir a barreira estéril do grau cirúrgico, sobretudo ao preparar artigos perfurantes, pesados ou com dimensões maiores, estes devem apresentar embalagens duplas e seladas ${ }^{1,2,6}$. Tais determinações apresentaram conformidade, porque a montagem dos PPS era padronizada e seguia as recomendações ${ }^{2,6}$. Os PPS, em sua maioria, foram organizados na autoclave em conformidade, como o que foi verificado em Goiânia, estando dispostos os pacotes maiores na parte inferior da câmara e os menores na parte superior ${ }^{27}$.

Um estudo sobre controle da esterilização realizado em Tabriz, no Irã, por um período de 14 anos, constatou que houve resultado significativo quanto ao uso de indicadores químicos $^{28}$. Da mesma forma, foi observado que os integradores químicos eram utilizados e colocados nas caixas cirúrgicas, nos campos que recobrem o paciente, nos pacotes para procedimentos invasivos.

Verificou-se que o controle da esterilização das autoclaves era realizado diariamente, todavia a validação praticada era apenas química e biológica, sem verificação dos parâmetros físicos, devido à ausência de fita impressa e de registros. Tal ocorrência demonstra investimento financeiro insuficiente no setor de saúde e necessidade de controle dos gestores. Situação oposta foi encontrada em $60 \%$ das instituições públicas da cidade de Goiânia ${ }^{27}$.

Além disso, não existia rotina para desinfecção das autoclaves e superfícies, resultado preocupante, pois isso aumenta o risco de infecções cruzadas e ocupacionais, contrariando a recomendação de que todas as superfícies e os equipamentos devem ser desinfetados ${ }^{29}$.

Os produtos ao serem conduzidos para o setor de Guarda / Distribuição devem ser inspecionados quanto à umidade, integralidade, mudança de coloração do indicador externo e disposição nos armários/prateleiras em ordem cronológica de esterilização ${ }^{2}$. Estes itens foram observados em conformidade, exceto em relação à ordem cronológica de esterilização, dado semelhante ao estudo realizado em Goiânia, onde um estabelecimento de saúde realizou o processo adequadamente ${ }^{27}$. Essa desconformidade pode ser um fator contributivo para o aumento dos custos da assistência à saúde.

A Monitorização dos processamentos dos artigos no CME é complexa e exige atenção específica desde a limpeza até a sua distribuição, por isso as instituições devem planejar os trabalhos de acordo com paradigmas de qualidade e segurança do paciente.

Enfim, é função do enfermeiro não apenas ter conhecimento técnico-científico sobre o funcionamento do CME, mas, principalmente, coordenar, orientar, supervisionar, estimular e apoiar o aperfeiçoamento técnico-científico dos profissionais de enfermagem, cumprindo suas funções de forma ética e em observância aos princípios norteadores da profissão. 
Refere-se como limitação deste estudo a discussão pouco comparativa entre os estados brasileiros e outros países pela escassez de artigos com abordagem em âmbito internacional sobre esse tema.

\section{CONCLUSÃO}

Os cálculos dos índices de conformidades dos processos de trabalho dos PPS hospitalares no CME permitiram concluir que a média de conformidade apresentou índices sofríveis de classificação pelo IPC. No entanto, esses processos apresentaram-se comprometidos pela deficiência na estrutura física, ausência de capacitações periódicas e supervisão do enfermeiro.

A análise geral do processo de trabalho da equipe de enfermagem em um CME de um hospital de ensino no Nordeste brasileiro agrega conformidades e desconformidades semelhantes aos estudos realizados nas demais regiões brasileiras, em descumprimento às normas nacionais e internacionais vigentes, principalmente nos serviços públicos e em relação ao investimento destinado ao serviço de saúde e, em especial, ao CME.

Os resultados obtidos traduzem a necessidade de maior investimento na estrutura física, insumos, políticas e práticas de educação continuada, a fim de abolir falhas nos processos necessários para uma assistência segura aos pacientes.

\section{REFERÊNCIAS}

1. Ascari RA, Vidori J, Moretti CA, Perin EMF, Silva OM, Buss E. O processo de esterilização de materiais em serviços de saúde: uma revisão integrativa. Braz J Surg Clin Res. 2013;4(2):33-8.

2. Associação de Enfermeiros de Centro Cirúrgico, Recuperação Anestésica e Centro de Material e Esterilização (SOBECC). Diretrizes de práticas em enfermagem cirúrgica e processamento de produtos para a saúde. 7a ed. São Paulo: SOBECC; Barueri: Manole; 2017. p. 7-180.

3. Brasil. Agência Nacional de Vigilância Sanitária (ANVISA). RDC nº 15, de 15 de março de 2012. Dispõe sobre requisitos de boas práticas para o processamento de produtos para saúde e dá outras providências [Internet]. 2012 [acessado em 10 ago. 2017]. Disponível em: http:// www.anvisa.gov.br

4. Donabedian A. The quality of care. JAMA. [Internet]. 1998;260(12):17438. http://doi.org/10.1001/jama.1988.03410120089033

5. Graziano KU, Lacerda RA, Turrini RTN, Bruna CQM, Silva CPR, Schmitt C, et al. Indicadores de avaliação do processamento de artigos odonto-médicohospitalares: elaboração e validação. Rev Esc Enferm USP. 2009;43(N. Esp. 2):1174-80. https://doi.org/10.1590/S0080-62342009000600005

6. Association for the Advancement of Medical Instrumentation (AAMI). America national standard comprehensive guide to steam sterilization and sterility assurance in health care facilities. Advancing Safety in Medical Technology A4. Arlington: AAMI; 2013.

7. Provincial Infectious Diseases Advisory Committee (PIDAC). Best practices for cleaning, disinfection and sterilization of medical equipment/devices [Internet]. $3^{\text {rd }}$ ed. Toronto, ON: Queen's Printer for Ontario; 2013 [acessado em 17 dez. 2018]. Disponível em: https:// www.publichealthontario.ca/en/BrowseByTopic/InfectiousDiseases/ PIDAC/Pages/Cleaning_Disinfection_Sterilization.aspx

8. Morton PJ, Conner R. Implementing AORN. Recommended practices for selection and use of packaging systems for sterilization. AORN J [Internet]. 2014 [acessado em 17 set. 2018];99(4):495-505. Disponível em: https://www.ncbi.nlm.nih.gov/pubmed/24674795 https://doi.org/10.1016/j.aorn.2014.02.014

9. Padilha EF, Matsuda LM. Qualidade dos cuidados de enfermagem em terapia intensiva: avaliação por meio de auditoria operacional. Rev Bras Enferm. 2011;64(4):684-91.

10. Conselho Federal de Enfermagem (COFEN). Pesquisa perfil daenfermagem no Brasil [Internet]. Rio de Janeiro: COFEN; 2013 [acessado em 21 abr. 2018]. Disponível em: http://www.cofen.gov.br/perfilenfermagem

11. Costa CCP, Souza NVDO, Pires AS. Perfil dos trabalhadores de uma central de material e esterilização: uma análise das características sócioprofissionais. J Res Fundam Care Online [Internet]. 2016 [acessado em 17 jan. 2018];8(1):3633-45. Disponível em: http://www.seer.unirio.br/ index.php/cuidadofundamental/article/view/3667/pdf_1768 http://doi.org/10.9789/2175-5361.2016.v8i1.3633-3645

12. Roseira CE, Silva DM, Passos IPBD, Orlandi FS, Padoveze MC, Figueiredo RM. Diagnosis of compliance of health care product processing in primary health care. Rev Latino-Am Enferm [Internet]. 2016 [acessado em 30 jan. 2018];24:e2820. Disponível em: http://www.scielo.br/scielo. php?script=sci_arttext\&pid=S0104-11692016000100426\&lng=en https://doi.org/10.1590/1518-8345.1439.2820

13. Costa EAM, Dórea EO, Alves MA, Nery F, Schettini H, Belmonte M, et al. Reprocessamento de produtos para saúde: análise da qualidade sanitária em hospitais públicos. Rev SOBECC. 2015;20(1):17-23. https://doi.org/10.5327/Z1414-4425201500010003

14. Madeira MZA, Santos AMR, Batista OMA, Rodrigues FTC. Processamento de produtos para saúde em centro de material e esterilização. RevSOBECC. 2015;20(4):220-7. https://doi.org/10.5327/Z1414-4425201500040006

15. Petersen BT, Cohen CJ, Hambrick R, Buttar N, Greenwald DA, Buscaglia JM, et al. Multisociety guideline on reprocessing flexible $\mathrm{gl}$ endoscopes: 2016 update. Gastrointest Endosc [Internet]. 2017 [acessado em 11 set. 2018];85(2):282-94. Disponível em: http://www. giejournal.org/article/S0016-5107(16)30647-2/fulltext https://doi.org/10.1016/j.gie.2016.10.002 
16. Brasil. Ministério do Trabalho. Norma Regulamentadora 6 - NR 6. Equipamento de proteção individual (EPI). Manual de legislação Atlas Segurança e Medicina do Trabalho. 71ª ed. São Paulo: Atlas; 2013.

17. Freire EMR, Martinez MR. Situational diagnosis: an aid tool in quality management. J Nurs UFPE on line. 2014;8(5):1405-12. https://doi. org/10.5205/1981-8963-v8i5a9827p1405-1412-2014

18. Espindola MCG, Fontana RT. Riscos ocupacionais e mecanismos de autocuidado do trabalhador de um centro de material e esterilização. Rev Gaúcha Enferm. 2012;33(1):116-23. https://doi.org/10.1590/ S1983-14472012000100016

19. Brasil. DATASUS - Tecnologia da Informação a Serviço do SUS [Internet]. Brasília: Ministério da Saúde; 2010 [acessado em 21 abr. 2018]. Disponível em: http://tabnet.datasus.gov.br/cgi/tabcgi. exe?ibge/censo/cnv/escbRS.def

20. Cowperthwaite L, Holm RL. Guideline implementation: surgical instrument cleaning. AORN J [Internet]. 2015 [acessado em $17 \mathrm{dez}$. 2018];101(5):542-52. Disponível em: https://www.ncbi.nlm.nih.gov/ pubmed $/ 25946180$

https://doi.org/10.1016/j.aorn.2015.03.005

21. Turco M, Chalaye C, Poulard E, Gocko C, Neyron C, Courbon G, et al. Évaluation de l'impact d'une formation pluridisciplinaire sur le bon usage des gants à l'hôpital Médecine et Maladies Infectieuses [Internet]. 2014 [acessado em 20 fev. 2018];44(6):268-74. Disponível em: https://doi.org/10.1016/j.medmal.2014.04.001

22. Mansur JM. Reuse of single-use devices: understanding risks and strategies for decision-making for health care organizations [Internet]. Joint Commission International; 2017 [acessado em 12 out. 2018]. Disponível em: https://www.jointcommissioninternational.org/news/ reuse-of-single-use-devices

23. McDonnell G, Dehen C, Perrin A, Thomas V, Igel-Egalon A, Burke $\mathrm{PA}$, et al. Cleaning, disinfection and sterilization of surface prion contamination. J Hosp Infect [Internet]. 2013 [acessado em 2 fev. 2018];85(4):268-73. Disponível em: https://www.ncbi.nlm.nih.gov/ pubmed/24074640

https://doi.org/10.1016/j.jhin.2013.08.003

24. Schwaab G, Jacoby AM, Lunkes JT, Ascari RA, Lautert L. Esterilização de produtos para saúde em serviços públicos. Recife. Rev Enferm UFPE online [Internet]. 2016 [acessado em 2 ago. 2018];10(12):4591-8. Disponível em: https://doi.org/10.5205/ reuol.9978-88449-6-ED1012201621

25. Araujo GM, Reisdorfer N, Silva LA, Soder RM, Santos AM. Segurança do paciente: embalagens, acondicionamento e tempo de guarda de materiais esterilizados na atenção básica. Ciênc Cuid Saúde. 2016;15(4):662-8. https://doi.org/10.4025/cienccuidsaude.v15i4.29925

26. Tomé MF, Lima AFC. Mapeamento do processo de reprocessamento de campos cirúrgicos de tecido de algodão. Rev SOBECC. 2015;20(4):197201. https://doi.org/10.5327/Z1414-442520150004003

27. Mendonça ACC, Bezerra ALQ, Tipple AFV, Tobias GC. Indicadores de qualidade de processamento de produtos para a saúde em autoclaves a vapor. Rev Enferm UFPE on line [Internet]. 2017 [acessado em 20 mar. 2018];11(Supl. 2):906-14. Disponível em: https://periodicos. ufpe.br/revistas/revistaenfermagem/article/viewFile/13459/16148 https://doi.org/10.5205/reuol.10263-91568-1-RV.1102sup201705

28. Jabbari H, Alikhah H, Alamdari NS, Behzad MN, Mehrabi E, Borzui $\mathrm{L}$, et al. Developing the use of quality indicators in sterilization practices. Iran J Public Health [Internet]. 2012 [acessado em 20 mar. 2018];41(7):64-9. Disponivel em: https://www.ncbi.nlm.nih.gov/pmc/ articles/PMC3469009/

29. Rutala WA, Weber DJ. Monitoring and improving the effectiveness of surface cleaning and disinfection. Am J Infection Control [Internet]. 2016 [acessado em 20 jan. 2018];44(5 Supl.):e69-e76. Disponível em: https://www.ncbi.nlm.nih.gov/pubmed/27131138 https://doi.org/10.1016/j.ajic.2015.10.039 